\title{
Modelling the performance of a SiC-based synchronous boost converter using different conduction modes
}

\author{
Maria R. Rogina, Alberto Rodriguez, Aitor Vazquez, Diego G. Lamar, Marta M. Hernando \\ Electronic Power Supply Systems Group \\ University of Oviedo \\ Campus de Viesques, s/n, 33204. Gijon, Spain \\ rodriguezrmaria@uniovi.es
}

\begin{abstract}
A SiC-based synchronous boost DC/DC converter rated for $400 \mathrm{~V}$ to $800 \mathrm{~V}$ and $10 \mathrm{~kW}$ with high efficiency in a wide power range, especially at medium and light load, is designed and developed. The better switching performance of SiC MOSFETs allows the use of high switching frequency operation modes even at voltage close to $1 \mathrm{kV}$ (previously avoided due to the high switching losses introduced by silicon IGBTs). The distribution of the converter losses at different conduction modes and frequencies is evaluated. Moreover, digital control makes easier modifications of the operation mode in order to optimize the efficiency for different loads. Consequently, different operation modes (conduction mode and switching frequency) for different loads are compared in order to provide a design guide to optimize the converter performance in all the power range.
\end{abstract}

Keywords-DC/DC bidirectional converters, light load operation, quasi-square wave $(\mathrm{QSW})$, silicon carbide (SiC) MOSFETS.

\section{INTRODUCTION}

Power Electronics Transformers (PETs) have been proposed as a semiconductor based alternative to conventional Line-Frequency Transformers (LFTs) [1]-[4]. A fully modular three stage approach $(\mathrm{AC} / \mathrm{DC}+\mathrm{DC} / \mathrm{DC}+\mathrm{DC} / \mathrm{AC})$ appears to be the most popular choice [2], [5]-[9], being very common the use of multilevel converters to develop the AC/DC stage of the PET, as in the case CHB-based PET [9] and MMC-based PET [10], [11]. Multilevel converters provide a high voltage DC link without a bulk DC capacitor, being the distributed energy storage at the cell capacitors, which is advantageous for safety and reliability reasons [12]. By adequate design of the cells, it is possible to integrate low voltage dc or ac power sources (such as PV panels or wind turbines), loads or energy storage devices at the cell level [13]-[15]. However, if the voltage level of the cell (usually, around $1 \mathrm{kV}$ ) and the voltage level of the storage system are different, the use of bidirectional power converters is mandatory to adapt the energy format (Figure 1). Battery charging process is usually done in three stages [16], with a final stage in which the charging current is very low and high efficiency is paramount importance in PETs. Therefore, the power converter connecting the battery with the PET cell must withstand high voltage providing high efficiency over a wide power range

Wide Band Gap (WBG) semiconductors, especially Silicon Carbide (SiC) MOSFETs, allow the operation of power converters at high voltage and high switching frequency with high efficiency [17]. SiC MOSFETs and a variable switching frequency control technique providing Zero Voltage Switching (ZVS) have been used to improve the efficiency in a synchronous boost converter, especially at medium and light load operating at high voltage and high frequency [18], [19]. However, a high current ripple is the price to pay of the proposed operation mode, which increases conduction losses, especially at full load.

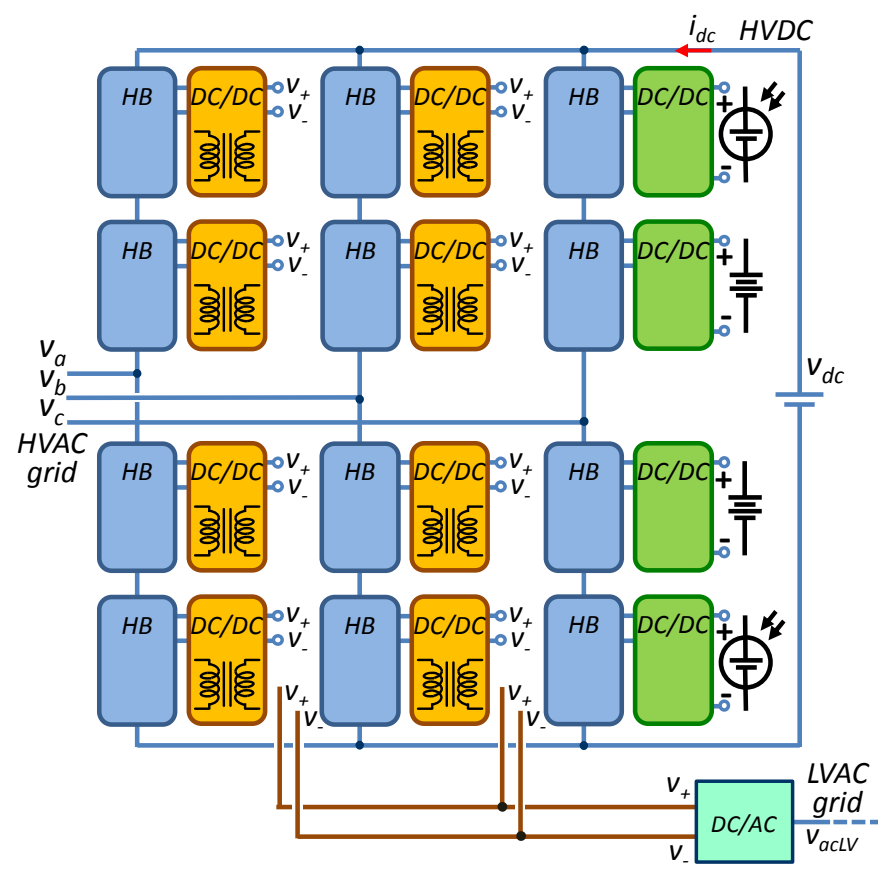

(a) 


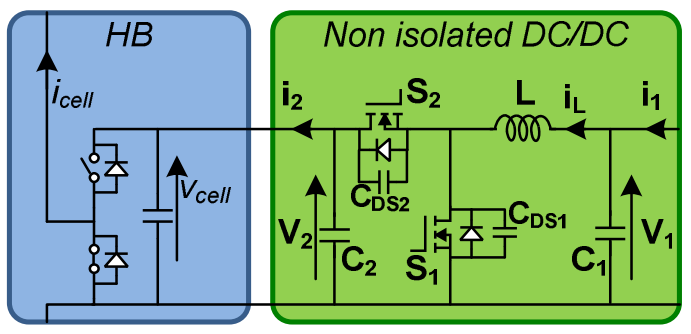

(b)

Figure 1. (a) Distributed energy sources integration in a MMC. (b) Structure of the cell.

Nowadays, most of the high-power converters are digitally controlled, making possible modifications of the operation mode. In this paper, the conduction mode to achieve the maximum attainable performance of a $\mathrm{SiC}$-based synchronous boost converter is evaluated. The proper design of the inductor, the conduction mode and the switching frequency for different power ranges are proposed. Although this work is oriented to develop a bidirectional converter able to provide energy storage capability to a PET, the extracted conclusions can also be applied to other applications where a bidirectional converter with high efficiency and high voltage operation is needed.

The proposal of this work is to evaluate the feasibility of a synchronous boost converter using different conduction modes and switching frequencies in function of the transferred power in order to improve its performance in a wide power range. Three different conduction modes are analyzed and the converter losses operating in each conduction are estimated in Section II. Furthermore, experimental results of a prototype working in the proposed conduction modes are presented in Section III. Finally, Section IV proposes a design and a control strategy to improve the performance of the converter modifying the conduction mode and the switching frequency for different power values.

\section{ANALYSIS OF THE DIFFERENT CONDUCTION MODES}

The synchronous boost converter is the bidirectional DC/DC topology without galvanic isolation using the lowest number of power devices (Figure 1, green converter). Different control strategies have been proposed for this topology.

\section{A. Characteristics of the analyzed modes}

A summary of the characteristics of the three analyzed continuous conduction modes (CCM) is presented and their key waveforms are shown in Figure 2.

1) CCM hard switching (CCM-HS). Reduced current ripple (inductance current always positive) and constant switching frequency (f). Its key advantage is the low current ripple (suitable for charging and discharging energy storage systems), performing low conduction losses. High switching losses are the main drawback. At light loads, this mode achieves ZVS (Triangular Conduction Mode (TCM)).

2) Boundary Conduction Mode with Zero Current Switching (BCM-ZCS). Large current ripple (inductance current is zero at the turn-on of $\mathrm{S}_{1}$ ) and variable switching frequency. Switching losses are reduced but, due to the large current ripple, conduction losses are increased [20] - [23].

3) Quasi-Square Wave mode with Zero Voltage Switching (QSW-ZVS) [24] - [27]. Large current ripple (inductance current is negative at the turn-on of $S_{1}$ ) and variable switching frequency. Full ZVS can be achieved for certain relations of input and output voltages [24], reducing switching losses but also increasing conduction losses.

Analytical models for the estimation of the efficiency of a boost converter operating in the three specified conduction modes are developed and experimentally validated.

\section{B. Distribution of the converter losses}

The sources of losses considered in this work are conduction, switching, gate and inductor losses. In TABLE I, switching losses are detailed for the different operation modes. No reverse recovery losses are taken into consideration, since it is a synchronous boost converter working with $\mathrm{SiC}$ MOSFETs which include $\mathrm{SiC}$ diodes in antiparallel and those losses can be negligible.
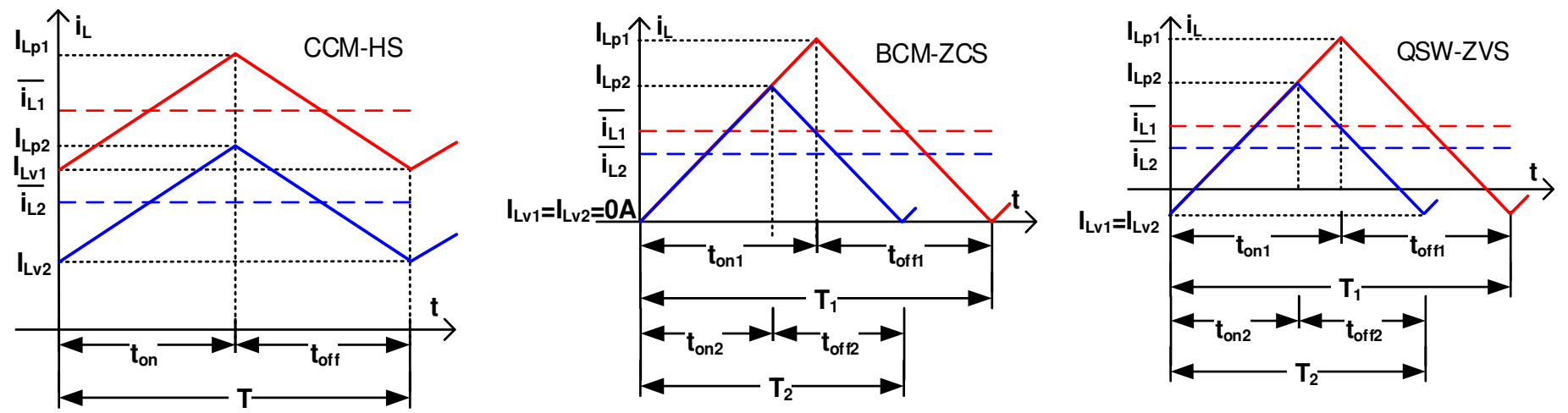

Figure 2. Inductor current waveform for two different power levels. 
TABLE I. Distribution of switching losses

\begin{tabular}{|c|c|c|c|c|}
\cline { 2 - 5 } \multicolumn{1}{c|}{} & \multicolumn{4}{c|}{ Switching } \\
\cline { 2 - 5 } \multicolumn{1}{c|}{} & \multicolumn{2}{c|}{$\mathrm{S}_{1}$} & \multicolumn{2}{c|}{$\mathrm{S}_{2}$} \\
\cline { 2 - 5 } \multicolumn{1}{c|}{} & $\begin{array}{c}\text { ON } \\
(\mathrm{k} 1)\end{array}$ & $\begin{array}{c}\text { OFF } \\
(\mathrm{k} 2)\end{array}$ & $\begin{array}{c}\text { ON } \\
(\mathrm{k} 3)\end{array}$ & $\begin{array}{c}\text { OFF } \\
(\mathrm{k} 4)\end{array}$ \\
\hline CCM-HS & 1 & 1 & 0 & 1 \\
\hline TCM & 0 & 1 & 0 & 1 \\
\hline BCM-ZCS & 1 & 1 & 0 & 1 \\
\hline QSW-ZVS & 0 & 1 & 0 & 0 \\
\hline
\end{tabular}

$S_{1}$ and $S_{2}$ conduction losses are calculated by means of the conduction resistance $\left(\mathrm{R}_{\mathrm{dson}}\right)$ and the rms current $\left(\mathrm{I}_{\mathrm{rms}}\right)$ going through each MOSFET, and they are respectively given by:

$$
\begin{aligned}
& \mathrm{P}_{\mathrm{c} \_\mathrm{S} 1}=\mathrm{R}_{\mathrm{dson} \_\mathrm{S} 1} \cdot \mathrm{I}_{\text {rms_S} 1}{ }^{2} \\
& \mathrm{P}_{\mathrm{c} \_\mathrm{S} 2}=\mathrm{R}_{\text {dson_S2}} \cdot \mathrm{I}_{\text {rms_S2 }}{ }^{2}
\end{aligned}
$$

The main difference in efficiency among the different conduction modes for a concrete load comes from the switching losses, which are conferred on:

$$
\begin{aligned}
& \mathrm{P}_{\mathrm{sw}_{\text {}} \mathrm{S} 1}=\mathrm{f} \cdot\left(\mathrm{k}_{1} \cdot \mathrm{E}_{\mathrm{on} \_\mathrm{S} 1}+\mathrm{k}_{2} \cdot \mathrm{E}_{\mathrm{off} \_\mathrm{S} 1}\right) \\
& \mathrm{P}_{\mathrm{sw} \_\mathrm{S} 2}=\mathrm{f} \cdot\left(\mathrm{k}_{3} \cdot \mathrm{E}_{\text {on_S2 }}+\mathrm{k}_{4} \cdot \mathrm{E}_{\text {off_S2 }}\right)
\end{aligned}
$$

where $\mathrm{k}_{\mathrm{i}}$ will take the value 0 or 1 depending on the conduction mode (see TABLE I). If $\mathrm{k}_{\mathrm{i}}$ is 0 , the switching losses in that transition (turn-on or turn-off) are considered negligible. By contrast, if $\mathrm{k}_{\mathrm{i}}$ is 1 , they are considered in the model.

Traditionally these switching losses were estimated by means of the output parasitic capacitance $\left(\mathrm{C}_{\mathrm{sw}}\right)$ and the turn-on and turn-off times ( $\mathrm{t}_{\mathrm{on}}$ and $\mathrm{t}_{\mathrm{off}}$, including rise and delay time). However, all these values are not constant and they can change either with the instant voltage or with working conditions.

On the other hand, the dissipated energies by the MOSFET in its turn-on and turn-of ( $E_{\text {on }}$ and $E_{\text {off }}$ energies, respectively) provide a more accurate approach to estimate its switching losses since their values can be easily obtained through the data provided by the manufacturer, as shown in Figure 3 . These energies are calculated using (5) - (8):

$$
\begin{aligned}
\mathrm{E}_{\text {on_S1 }} & =\left(\left|\mathrm{I}_{\mathrm{Lv}}\right| \cdot \mathrm{E}_{\text {on_Slope }}\right)+\mathrm{E}_{\text {on_constant }} \\
\mathrm{E}_{\text {off_S1 }} & =\left(\left|\mathrm{I}_{\mathrm{Lp}}\right| \cdot \mathrm{E}_{\text {off_Slope }}\right)+\mathrm{E}_{\text {off_constant }} \\
\mathrm{E}_{\text {on_S2 }} & =\left(\left|\mathrm{I}_{\mathrm{Lp}}\right| \cdot \mathrm{E}_{\text {on_Slope }}\right)+\mathrm{E}_{\text {on_constant }} \\
\mathrm{E}_{\text {off_S2 }} & =\left(\left|\mathrm{I}_{\mathrm{Lv}}\right| \cdot \mathrm{E}_{\text {off_Slope }}\right)+\mathrm{E}_{\text {off_constant }}
\end{aligned}
$$

being $\mathrm{I}_{\mathrm{Lp}}$ and $\mathrm{I}_{\mathrm{Lv}}$, the maximum and minimum inductor current (Figure 2).

Regarding gate losses, they are common for all conduction modes, and they are calculated for each device as:

$$
\mathrm{P}_{\text {gate }}=\mathrm{f} \cdot \mathrm{Q}_{\mathrm{g}} \cdot \Delta \mathrm{V}_{\mathrm{gs}}
$$

being $\mathrm{Q}_{\mathrm{g}}$ the sum of $\mathrm{Q}_{\mathrm{gd}}$ and $\mathrm{Q}_{\mathrm{gs}}$, and $\Delta \mathrm{V}_{\mathrm{gs}}$ the difference between the positive and the negative voltage applied to the gate-to-source terminals.

With regard to inductor losses, both copper $(\mathrm{Cu})$ and core (Co) losses are taken into account, being defined as follows:

$$
\begin{gathered}
\mathrm{P}_{\mathrm{Co}}=\left(\mathrm{V}_{\mathrm{e}} \cdot \alpha \cdot \mathrm{f}^{\beta}\right)\left[\left(\mathrm{L} \cdot \Delta \mathrm{I}_{\mathrm{L}}\right) /\left(2 \cdot \mathrm{N} \cdot \mathrm{A}_{\mathrm{e}}\right)\right]^{\gamma} \\
\mathrm{P}_{\mathrm{Cu}}=\rho_{\mathrm{o}} \cdot \mathrm{l}_{\mathrm{m}} \cdot \mathrm{I}_{\mathrm{Lrms}}{ }^{2} \cdot \mathrm{N} / \mathrm{S}_{\mathrm{e}}
\end{gathered}
$$

where $\mathrm{V}_{\mathrm{e}}$ is the effective volume of the bobbin, $\alpha, \beta$ and $\gamma$ are constants dependent on the core material, $\mathrm{L}$ is the inductor value, $\Delta \mathrm{I}_{\mathrm{L}}$ is the current ripple, $\mathrm{N}$ the number of turns and $\mathrm{A}_{\mathrm{e}}$ is the effective area of the bobbin.

The section of the cupper, $\mathrm{S}_{\mathrm{e}}$, is defined as:

$$
\mathrm{S}_{\mathrm{e}}=\mathrm{N}_{\mathrm{p}} \cdot \pi \cdot \mathrm{d}^{2} / 4
$$

being $\rho_{\mathrm{o}}$ the cupper resistivity, $1_{\mathrm{m}}$ the length of each turn of cupper, $\mathrm{N}_{\mathrm{p}}$ the number of threads in parallel and $\mathrm{d}$ the diameter of the thread.

It is also worth to mention that in the case of BCM-ZCS and QSW-ZVS, the switching frequency varies inversely proportional to the output power, being the maximum switching frequency $\left(\mathrm{f}_{\max }\right)$ limited by the output capacitance of power transistors. $f_{\max }$ determines the minimum power for BCM-ZCS and QSW-ZVS, given by:

$$
\mathrm{P}_{\mathrm{BCM} \text { min }}=\mathrm{V}_{1}^{2} \cdot \mathrm{D} / 2 \cdot \mathrm{L} \cdot 1 / \mathrm{f}_{\max }
$$

$$
\mathrm{P}_{\mathrm{QSW} \min }=\left(\mathrm{V}_{1} / 2\right) \cdot\left[(\mathrm{D}+\mathrm{B}-\mathrm{A}) \cdot \mathrm{I}_{\mathrm{Lp}}-(\mathrm{A}-\mathrm{D}+\mathrm{B}) \cdot \mathrm{I}_{\mathrm{Lv}}\right]
$$

being $\mathrm{D}$ the duty cycle and $\mathrm{A}$ and $\mathrm{B}$ are given by:

$$
\begin{gathered}
\mathrm{A}=-\mathrm{I}_{\mathrm{Lv}} \cdot \mathrm{L} /\left(\mathrm{V}_{1} / \mathrm{f}_{\max }\right) \\
\mathrm{B}=\mathrm{I}_{\mathrm{Lp}} \cdot \mathrm{L} /\left[\left(\mathrm{V}_{2}-\mathrm{V}_{1}\right) / \mathrm{f}_{\max }\right]
\end{gathered}
$$

Thanks to the low parasitic capacitances of SiC MOSFETs and the soft switching operation, the maximum attainable switching frequency is quite high (even at high voltages) allowing the use of BCM-ZCS and QSW-ZVS for very light loads.

Moreover, the use of SiC MOSFETs is almost mandatory due to the required values of voltage and switching frequency proposed in this application.

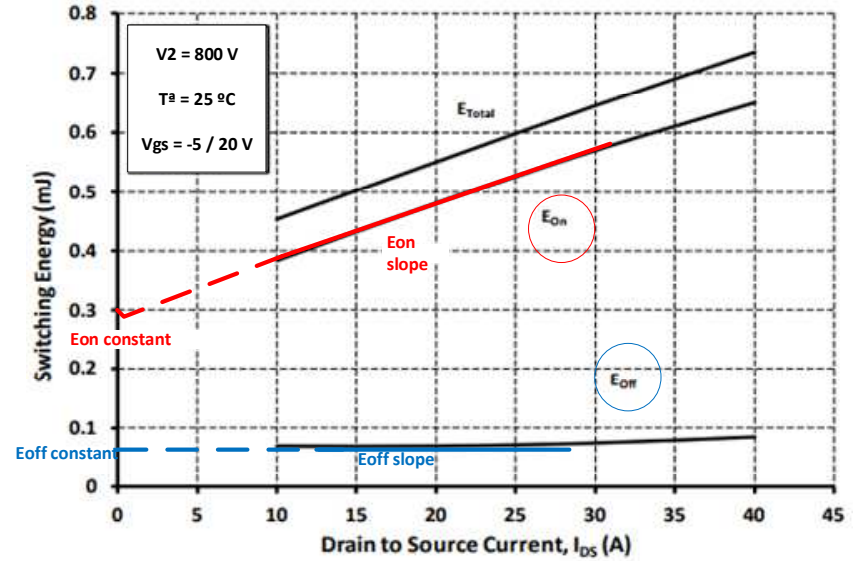

Figure 3. Energies given by the manufacturer ${ }^{\circledR}$ Wolfspeed 
Figure 4 and Figure 5 (as two examples of the information given by the models) show the variation of the frequency and the inductor current ripple ratio as a function of the power for the three analyzed conduction modes, respectively. As can be seen, for different power ranges, the switching frequency and the inductor current ripple are different for each conduction mode and consequently the converter losses are quite different.

The analytical estimation of the losses can determine the most efficient conduction mode for each power range. Being aware of the most efficient conduction mode and having a central control that allows switching among them, the converter can be designed to obtain high efficiency in a wide power range.

\section{EXPERIMENTAL RESULTS}

A bidirectional synchronous boost converter prototype has been designed and built (Figure 6) following the specifications shown in TABLE II (the main components are also included). As one of the main aspects in this work is achieving high efficiency over a wide power range, mainly for medium and light load, both analytical and experimental results are compared in Figure 7. For heavy loads, efficiencies are very similar for all the three modes considered, so experimental results up to $80 \%$ of full load are shown.

The highest efficiency is provided by QSW-ZVS, but also high current ripple, together with BCM-ZCS. However, to obtain QSW-ZVS in both power directions $V_{2}$ must be twice $\mathrm{V}_{1}$. Otherwise, only partial ZVS can be achieved [28]. BCMZCS is attained for any voltage relation and its practical implementation is easier (only zero crossing detection). If a higher frequency is used, a smaller current ripple is given in CCM-HS without an important decrease of the efficiency, especially at high load (Figure 7). However, CCM-HS is lost for lighter loads, becoming TCM, which means reaching ZVS at the expense of working with more reactive current. As can be seen, not only efficiency but also different variables should be considered before selecting a conduction mode for a given application. The developed models allow a comparison between different conduction modes at different power levels.

As proof of concept some experimental waveforms are shown in Figure 8 for two different load levels (one at light load and one at medium-high load) and the three conduction modes under study.

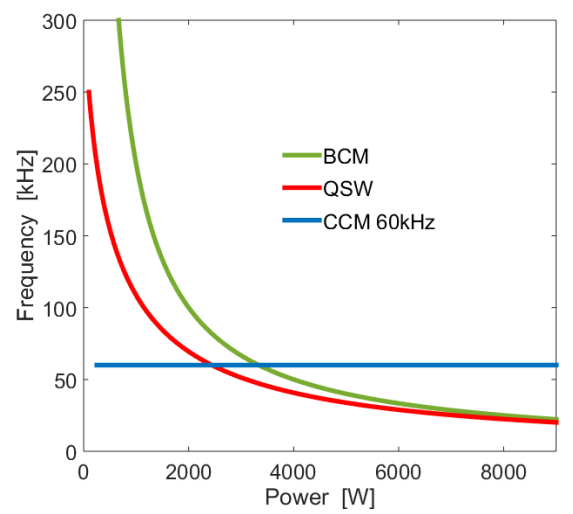

Figure 4. Switching frequency for different loads and different conduction modes.

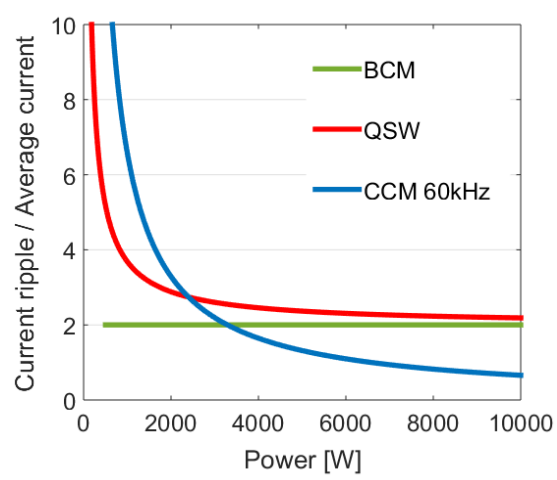

Figure 5. Inductor current ripple ratio for different loads and different conduction modes.

TABLE II. Converter specifications

\begin{tabular}{|l|c|}
\hline \multicolumn{1}{|c|}{ Parameter } & Values \\
\hline Input / Output voltages $\left(\mathrm{V}_{1} / \mathrm{V}_{2}\right)$ & $400 \mathrm{~V} / 800 \mathrm{~V}$ \\
\hline Maximum power $\left(\mathrm{P}_{\max }\right)$ & $10 \mathrm{~kW}$ \\
\hline $\begin{array}{l}\text { Minimum / maximum switching } \\
\text { frequency }\left(\mathrm{f}_{\min } / \mathrm{f}_{\max }\right)\end{array}$ & $20 \mathrm{kHz} / 200 \mathrm{kHz}$ \\
\hline Inductor $(\mathrm{L})$ & $\begin{array}{c}200 \mu \mathrm{H} \\
\text { bobbin: ETD } 59\end{array}$ \\
\hline MOSFET & $(3$ inductors of $600 \mu \mathrm{H}$ in parallel $)$ \\
\hline Driver & CCS020M12CM2 \\
\hline
\end{tabular}

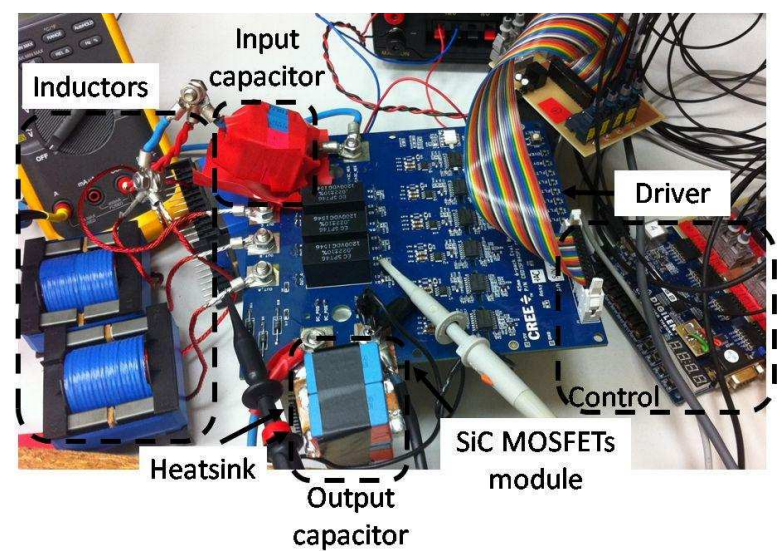

Figure 6. Experimental prototype

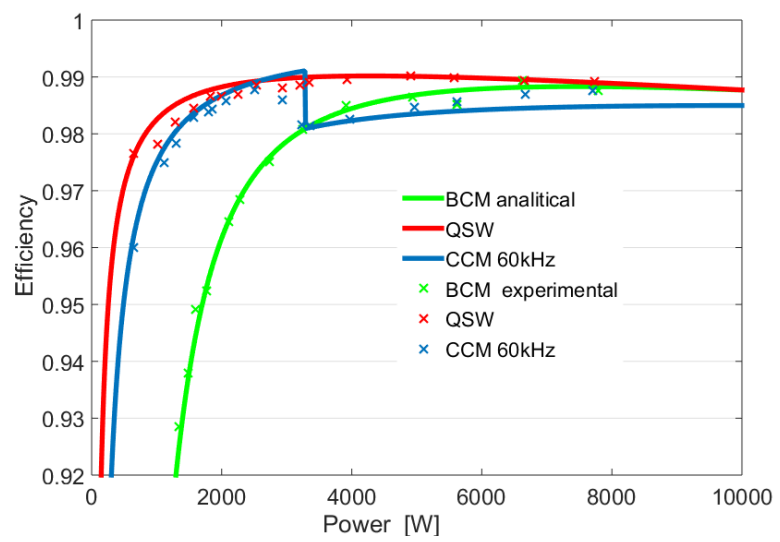

Figure 7. Analytical and experimental efficiency comparison. 

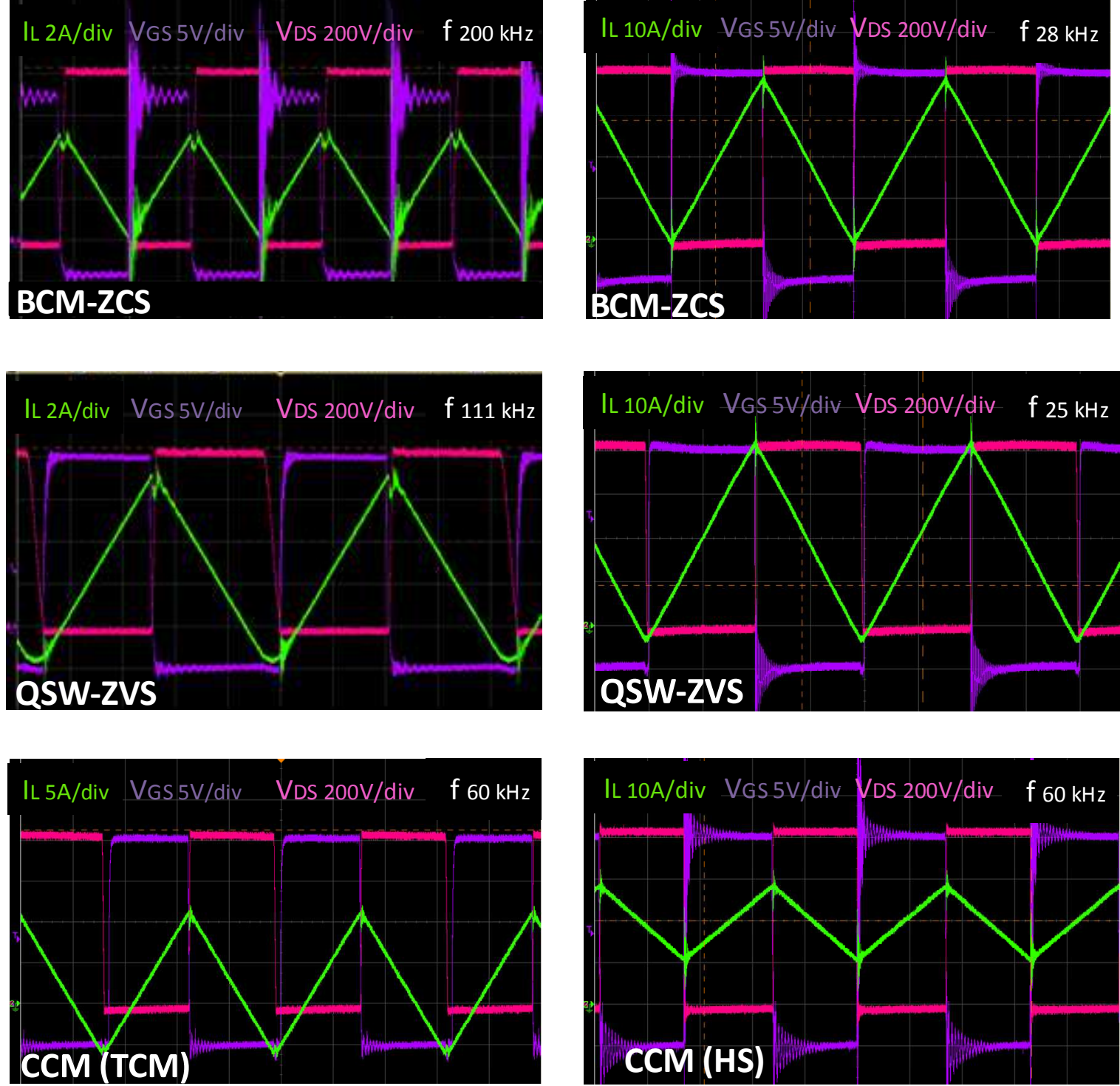

Figure 8. Experimental waveforms for the three analyzed modes and two different power levels.

\section{CONTROL STRATEGY}

In order to optimize the performance for the whole power range, a control based on switching among conduction modes for different load levels is applied.

The fact that efficiencies at high loads for the different conduction modes are considerably similar for this specific application (it is experimentally validated and shown in Figure 7) allows a control strategy based on other factors, such as, current ripple or peak current level.
So as to keep a limited current ripple and, therefore, a concrete peak current level through the MOSFETs, CCM-HS conduction mode is preferred for high loads (it also provides easier control since it works at a fixed frequency), switching to QSW-ZVS when the peak current level is similar to that of the CCM-HS at full load. For instance, if the peak current level at $9 \mathrm{~kW}$ is $30 \mathrm{~A}$ for CCM-HS, the control will change to QSW-ZVS when the load level goes under $5.5 \mathrm{~kW}$ (which corresponds to $30 \mathrm{~A}$ of peak current level for that conduction mode). 


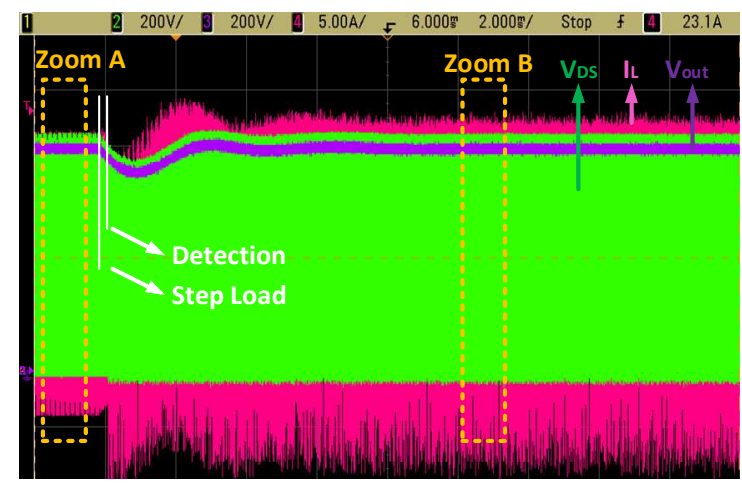

(a)

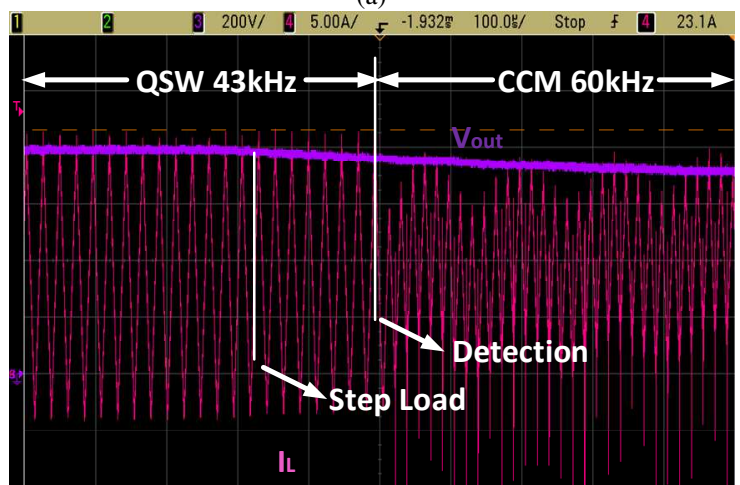

(b)

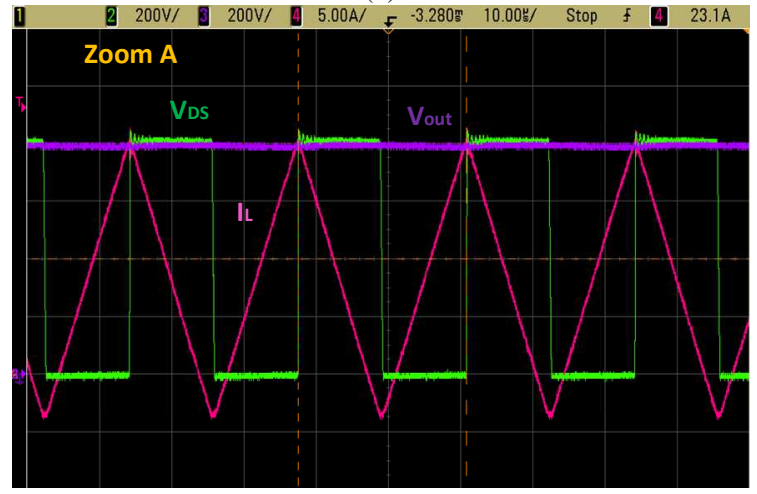

(c)

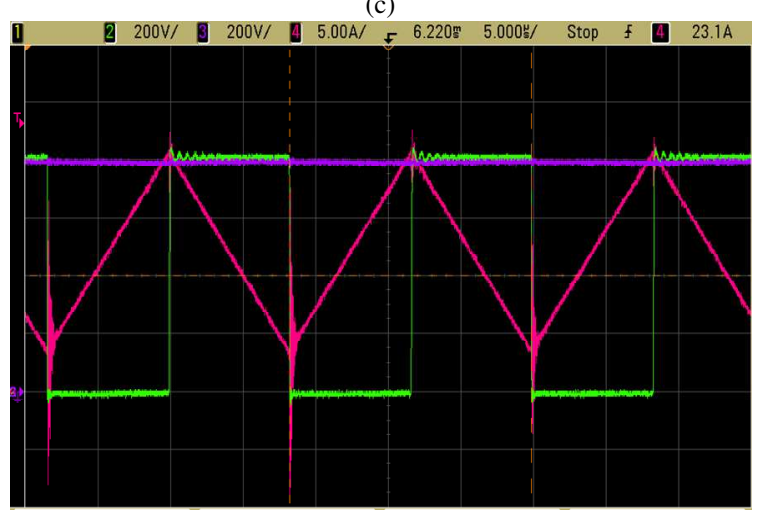

(d)

Figure 9. (a) Step load: $V_{D S}(V)$ in green, $I_{L}(A)$ in pink, $V_{\text {Out }}(V)$ in purple. (b) Detail of the step load switching between modes. (c) QSW mode at $3.5 \mathrm{~kW} / 43 \mathrm{kHz}$. (d) CCM mode at $5 \mathrm{~kW} / 60 \mathrm{kHz}$.
As an example, a step load going from $3.5 \mathrm{~kW}$ to $5 \mathrm{~kW}$ is performed and shown in Figure 9 a-d. Different strategies might be chosen. In this case, only the output voltage is sensed, but full control of the converter and the possibility of different strategies will be given sensing the inductor current. If the nominal voltage goes below or over a pre-stablished threshold, the frequency and duty cycle of the boost converter change accordingly to meet the new load requirements, guaranteeing always an output voltage of $800 \mathrm{~V}$.

In Figure $9 \mathrm{a} \mathrm{V}_{\mathrm{DS}}, \mathrm{I}_{\mathrm{L}}$ and $\mathrm{V}_{\mathrm{OUT}}$ are displayed. It is seen that, even if the detection of the step load is done within the first $200 \mu$ s, the dynamic of the converter causes a slight voltage imbalance during approximately $7 \mathrm{~ms}$. However, as it is reflected in Figure 9b, a smooth transition is obtained passing from QSW-ZVS operation mode at $43 \mathrm{kHz}$ for $3.5 \mathrm{~kW}$ to CCM-HS operation mode at $60 \mathrm{kHz}$ for $5 \mathrm{~kW}$. In this sense, CCM-HS is preferred to QSW-ZVS, since it is desired to keep lower current peak through the inductor.

In Figure 9c, a zoom of the QSW-ZVS mode is shown, noticing that noiseless commutations are achieved due to the ZVS condition. Likewise, Figure $9 d$ shows a zoom of the CCM-HS mode. In this case, hard switching commutations are obtained. Nevertheless, lower current ripple is accomplished.

\section{CONCLUSIONS}

Three different conduction modes in a SiC-based synchronous boost converter are presented and compared in this work. Both theoretical and experimental results are shown and good match between them is obtained.

The models help the designer in the selection of the conduction mode for different specifications. The highest efficiency is obtained with QSW-ZVS, but its high current ripple, especially at high loads, can decrease the performance of the converter for certain applications. Therefore, in this particular application our proposal is the use of CCM-HS for high loads (due to its lower ripple), switching to QSW-ZVS (or BCM-ZCS, if the specification of $V_{2}=2 \cdot V_{1}$ is not accomplished, since QSW-ZVS requires this condition for a proper operation) for medium and light loads.

As a proof of concept, a step load between two different power levels is shown, evidencing that the transition from one condition mode to another one can be automatically done successfully.

\section{ACKNOWLEDGMENT}

This work was carried out by funding from the Government of Spain through projects DPI2013-47176-C2-2-R, MINECO15-DPI2014-56358-JIN and the grant FPI BES-2014-070785, through funding from the Government of Asturias through the project FC-15-GRUPIN14-143 and FEDER funds. 


\section{REFERENCES}

[1] Ronan, E.R.; Sudhoff, S.D.; Glover, S.F.; Galloway, D.L., "A power electronic-based distribution transformer," in Power Delivery, IEEE Transactions on , vol.17, no.2, pp.537-543, Apr 2002

[2] van der Merwe, J.W.; du T. Mouton, H.; , "The solid-state transformer concept: A new era in power distribution," AFRICON, 2009. AFRICON '09. , vol., no., pp.1-6, 23-25 Sept. 2009

[3] Jih-Sheng Lai; Maitra, A.; Mansoor, A.; Goodman, F.; , "Multilevel intelligent universal transformer for medium voltage applications," Industry Applications Conference, 2005. Fourtieth IAS Annual Meeting. Conference Record of the 2005 , vol.3, no., pp. 1893- 1899 Vol. 3, 2-6 Oct. 2005

[4] Xu She; Huang, A., "Solid state transformer in the future smart electrical system," in Power and Energy Society General Meeting (PES), 2013 IEEE , vol., no., pp.1-5, 21-25 July 2013

[5] J. Kolar and G. Ortiz, "Solid-state-transformers: key components of future traction and smart grid systems," in Proc. Of the International Power Electronics Conference (IPEC), Hiroshima, Japan, 2014

[6] Falcones, S.; Xiaolin Mao; Ayyanar, R., "Topology comparison for Solid State Transformer implementation," Power and Energy Society General Meeting, 2010 IEEE , vol., no., pp.1,8, 25-29 July 2010

[7] Advanced Power Converter for Universal and Flexible Power Management in Future Electricity Networks, UNIFLEX. FP6, EC Contract n: 019794 (SES6) EUROPEAN COMMISSION, DIRECTORATE J-ENERGY

[8] Zhao, T.; Wang, G.; Bhattacharya, S.; Huang, A. Q., "Voltage and Power Balance Control for a Cascaded H-Bridge Converter-Based Solid-State Transformer," Power Electronics, IEEE Transactions on , vol.28, no.4, pp.1523,1532, April 2013

[9] $\mathrm{Xu}$ She; Lukic, S.; Huang, A.Q.; Bhattacharya, S.; Baran, M.; , "Performance evaluation of solid state transformer based microgrid in FREEDM systems," Applied Power Electronics Conference and Exposition (APEC), 2011 Twenty-Sixth Annual IEEE , vol., no., pp.182-188, 6-11 March 2011

[10] Shojaei, A.; Joos, G., "A topology for three-stage Solid State Transformer," in Power and Energy Society General Meeting (PES), 2013 IEEE , vol., no., pp.1-5, 21-25 July 2013

[11] Briz, F.; Lopez, M.; Rodriguez, A.; Zapico, A.; Arias, M.; DiazReigosa, D., "MMC based SST," in Industrial Informatics (INDIN), 2015 IEEE 13th International Conference on , vol., no., pp.1591-1598, 22-24 July 2015

[12] Rohner, S.; Bernet, S.; Hiller, M.; Sommer, R.; "Analysis and Simulation of a $6 \mathrm{kV}, 6 \mathrm{MVA}$ Modular Multilevel Converter", IEEE Industrial Electronics Conference (IECON). p. 225-230, 3-5 Nov. 2009.

[13] Vasiladiotis, M.; Rufer, A., "Analysis and Control of Modular Multilevel Converters With Integrated Battery Energy Storage," Power Electron., IEEE Trans. on , vol.30, no.1, pp.163,175, Jan. 2015

[14] M. A. Perez, D. Arancibia, S. Kouro and J. Rodriguez, "Modular multilevel converter with integrated storage for solar photovoltaic applications," Industrial Electronics Society, IECON 2013 - 39th Annual Conference of the IEEE, Vienna, 2013, pp. 6993-6998.

[15] R. Abhinav and N. M. Pindoriya, "Grid integration of wind turbine and battery energy storage system: Review and key challenges," 2016 IEEE 6th International Conference on Power Systems (ICPS), New Delhi, 2016, pp. 1-6.

[16] K. Young, C. Wang, L. Y. Wang and K. Strunz, "Chapter 2 - Electric Vehicle Battery Technologies," in Electric Vehicle Integration into Modern Power Networks, New York, Springer New York, 2013, pp. 1556.

[17] José Millán; Philippe Godignon; Xavier Perpiñà; Amador Pérez-Tomás; José Rebollo, "A survey of wide bandgap power semiconductor devices", in Power Electronics, IEEE Transactions on, vol.29, no.5, May 2014.

[18] A. Vazquez; A. Rodriguez; M. R. Rogina; D. G. Lamar, "Different Modular Techniques Applied in a Synchronous Boost Converter with SiC MOSFETs to Obtain High Efficiency at Light Load and Low Current Ripple," in IEEE Transactions on Industrial Electronics , vol.PP, no.99, pp.1-1

[19] A. Rodriguez; A. Vazquez; M. R. Rogina; F. Briz, "Synchronous Boost Converter with High Efficiency at Light Load using QSW-ZVS and SiC MOSFETs," in IEEE Transactions on Industrial Electronics , vol.PP, no.99, pp.1-1

[20] Yang, L.; Zhang, Y.; Lee, C.Q., "A family of constant-switchingfrequency quasi-square-wave converters," Electrical and Computer Engineering, 1993. Canadian Conference on, vol., no., pp.309,312 vol.1, 14-17 Sep 1993.

[21] Yang, L.; Zhang, Y.F.; Lee, C.Q., "Analysis of the boost constantfrequency quasi-square-wave converters," Circuits and Systems, 1994., Proceedings of the 37th Midwest Symposium on, vol.2, no., pp.1172,1175 vol.2, 3-5 Aug 1994.

[22] Maksimovic, D., "Design of the zero-voltage-switching quasi-squarewave resonant switch," Power Electronics Specialists Conference, 1993. PESC '93 Record., 24th Annual IEEE, vol., no., pp.323,329, 20-24 Jun 1993.

[23] C. Marxgut, J. Biela and J. W. Kolar, "Interleaved Triangular Current Mode (TCM) resonant transition, single phase PFC rectifier with high efficiency and high power density,"Power Electronics Conference (IPEC), 2010 International, Sapporo, 2010, pp. 1725-1732.

[24] Vorperian, V., "Quasi-square-wave converters: topologies and analysis," Power Electronics, IEEE Transactions on , vol.3, no.2, pp.183,191, Apr 1988.

[25] Costa, J.M.F.D.; Silva, M.M., "Small-signal models and dynamic performance of quasi-square-wave ZVS converters with voltage-mode and current-mode control," Circuits and Systems, 1995., Proceedings., Proceedings of the 38th Midwest Symposium on, vol.2, no., pp.1183,1188 vol.2, 13-16 Aug 1995.

[26] Jong-Bok Baek; Woo-In Choi; Bo-Hyung Cho, "Digital Adaptive Frequency Modulation for Bidirectional DC-DC Converter," Industrial Electronics, IEEE Transactions on, vol.60, no.11, pp.5167,5176, Nov. 2013.

[27] Knecht, O.; Bortis, D.; Kolar, J.W., "Comparative Evaluation of a Triangular Current Mode (TCM) and Clamp-Switch TCM DC-DC Boost Converters," Energy Conversion Congress and Exposition (ECCE 2016, IEEE), vol., no., pp., 18-22 September 2016.

[28] M. Kasper, R. M. Burkart, G. Deboy and J. W. Kolar, "ZVS of Power MOSFETs Revisited," in IEEE Transactions on Power Electronics, vol. 31, no. 12, pp. 8063-8067, Dec. 2016. 